implemented to increase preparedness? We compared their responses with a similar survey sent to consultant paediatricians responsible for their training.

Methods Mailshot with link to an online survey was mailed to all ST3 trainees in London and Eastern Deaneries. A further mailshot was sent to all college tutors for hospitals in the London Deanery. Trainees were emailed twice, in July 2012 and November 2013 meaning 2 different years of trainees were recruited. The college tutors were emailed just once in July 2012.

Results We received 73 trainee responses and 13 from consultants. ST3 trainees concerns were: 1) Concerns with leadership and decision making, 2) Night shifts without senior supervision, 3) Leading resuscitations, 4) Inability to perform procedures, (specifically neonatal intubation).

Most trainees felt they were not competent in dealing with common scenarios in community paediatrics, in particular safeguarding (69\%) and outpatients 66\%). They felt competent for general day-day work in general paediatrics (93\%) and neonates (93\%). The consultants felt trainees were lacking in their ability to run a neonatal resuscitation $(78 \%)$, had inadequate practical skills $(67 \%)$ and lacked in their leadership skills (56\%)

Acting up was identified as a way to better prepare trainees by both the trainees and trainers, however the majority of ST3s $(62 \%)$ had not acted-up as a registrar. Changes to current training with earlier exposure to child protection issues and extra time in neonates to improve procedural skills were also identified as ways to improve trainees' competence.

Conclusion Our data has identified specific areas where existing training could be altered or new training measures instigated to ensure that registrars feel better prepared for their new roles. Their concerns can be split into human and clinical factors. It is possible to address many of these issues in SHO years, making trainees more confident in leadership and delegation.

\section{G189(P) THE USE OF SIMULATION TO TEACH MEDICAL STUDENTS HOW TO RECOGNISE AND MANAGE A SICK CHILD - A CLUSTER RANDOMISED TRIAL}

${ }^{1} \mathrm{E}$ Harnik, ${ }^{1} \mathrm{~K}$ Mackay, ${ }^{2} \mathrm{H}$ Jacob, ${ }^{1} \mathrm{~B}$ Morrissey, ${ }^{1} \mathrm{~J}$ Moreiras. ${ }^{1}$ Paediatrics, Whittington Health, London, UK; ${ }^{2}$ Paediatrics, Barnet Hospital, London, UK

\subsection{6/archdischild-2015-308599.183}

Aims Many medical students lack confidence in their ability to recognise and manage acutely unwell patients, particularly children. With less time available for training and reduced exposure to sick children, simulation is being used effectively to develop technical and non-technical skills in postgraduate paediatric training.

Our aim was to evaluate the impact of a one-day paediatric simulation course on medical students' self-reported ability and confidence in recognising and managing sick children.

Method We conducted a cluster-randomised study of the impact of a novel undergraduate paediatric simulation course. All students undertaking their paediatric placement at a district general hospital over a six month period were invited to take part. Students were cluster randomised into the intervention (simulation) group or control group (standard paediatric attachment).

Students in the intervention group attended a one-day simulation course during the last week of their attachment. The course included clinical skills stations, a discussion on human factors, and five simulations of common paediatric emergencies, each followed by a structured debrief.
All participants completed a questionnaire at the end of their attachment and those in the intervention completed a further questionnaire after the simulation day.

The primary outcome measure was students' self-reported ability and confidence in recognising, assessing and managing sick children. The secondary outcome measured was their views on the course.

Results Sixty one students participated: 32 in the intervention group and 29 in the control group.

Self-assessed confidence in recognising a sick child was higher after the simulation course compared to controls (difference in confidence $0.75 / 5,95 \%$ CI $0.40-1.10, p=0.0002)$. Similarly, those in the intervention group were more confident in assessing and managing a sick child (difference in confidence 1.02/5, 95\% CI $0.74-1.31, \mathrm{p}<0.0001)$.

Six key themes were identified from the qualitative responses, including increased confidence in emergency situations and an appreciation of human factors. Students found the simulation useful and wanted it offered to all undergraduates during child health attachments.

Conclusion A one-day simulation course improves medical students' confidence in assessing and managing unwell children and is highly valued by students. Further studies are needed to evaluate its impact on clinical performance and confidence over time.

\section{G190(P) WHAT DO PAEDIATRICIANS AND GENERAL PRACTITIONERS THINK SHOULD BE INCLUDED IN THE UNDERGRADUATE PAEDIATRIC CURRICULUM?}

D Wylam, S Kempley, D Freeth. Medical Education, Barts and the London School of Medicine, London, UK

\subsection{6/archdischild-2015-308599.184}

Aims First presentations of paediatric illnesses normally occur in Primary Care, yet recent research from New Zealand (Pinnock and Jones, 2008) focused on hospital-based doctors' perspectives on what should be included in the undergraduate medical curriculum. Primary Care physicians may have different perspectives, which should also shape the education provided for medical students. This study aimed to elicit the opinions of both GPs and hospital-based paediatricians about the relative importance of various presentations and skills to the curriculum, while also establishing if there were any additional presentations or skills they felt should be added.

Method This questionnaire-based study in the UK replicated the NZ study of Pinnock and Jones by asking consultants in paediatrics to comment on the importance of their 25 paediatric presentations (e.g. a febrile infant, child with vomiting and/or diarrhoea). The study extended on the NZ study in two ways: by including General Practitioners (GPs) and by eliciting opinions on the degrees of competence in specific clinical skills that hospital paediatricians and GPs in the UK wish newly qualified doctors to possess.

Results Sixty-three responses were received and analysed (33 Paediatricians, 30 GPs). Results found an agreement between $\mathrm{NZ}$ and UK paediatricians as to the importance of the presentations provided, to the undergraduate curriculum $(69 \%$ or more answering very or quite important). In addition to the list provided, 12 suggested presentations were added. All the stated skills were also considered important to the curriculum, and 9 suggested additional skills were provided.

There was a statistically significant difference between the views of paediatricians and GPs as to the perceived importance of eight presentations and four skills. 
Conclusion There was much agreement between paediatricians and GPs, as to the perceived importance of some of the stated presentations and skills, to the undergraduate curriculum, but it was also found that some of their views differed. Primary Care physicians have different perspectives, which should also shape the education provided for medical students. Future curriculum research should look to include other relevant professions, aside from specialists.

\section{G191(P) SO YOU WANT TO BE A PAEDIATRICIAN?}

A Anpananthar, N Ware, C Kingdon, R Klaber. Trainee Committee, London Specialty School of Paediatrics, London, UK

\subsection{6/archdischild-2015-308599.185}

Background There are a number of different career pathways facing paediatric trainees including academia, time out of training and subspeciality training. The careers advice they receive is dependent on their trainers and the trainees accessing the available resources and networks. The Royal College of Paediatric and Child Health has careers fairs for recruitment into paediatrics and is currently actively developing its mentoring strategy for paediatricians. The aim of this study was to assess the need for a careers fair

Methods A pilot regional careers evening for level 1 paediatric trainees was held in May 2014. As our level 2 and 3 trainees have the opportunities for peer networking at the existing regional training, this pilot careers evening was only aimed at level 1 trainees. The evening included talks on career pathways and signposting with questions and answer sessions with experts. Anonymous feedback was collated at the end of the event and 5 months post-event.

Results Of the 21 trainees who attended, 27\% had not had careers advice to date. $100 \%$ found the evening useful and all left with an action plan to explore their career options. Positive free text feedback included 'asking questions in informal manner, with immediate answers'; 'demystifying the Grid/general level 3 process'; 'discussion of different options available'; 'encouraged thinking about career plans'.

Of the $47 \%$ response to the post-event survey, trainees had sought careers advice from their educational supervisors or tertiary units, had become involved in management activities and looked into out of programme options. All had attributed these actions to the careers evening and most found the evening ' $u s e$ ful' or 'inspiring'.

These results were discussed in focus groups, comprised of training programme directors, college tutors, trainee committee members and trust representatives, to shape the programme for the next paediatric careers event.

Conclusion The feedback was overwhelmingly positive with high demand for it to be held annually in our region. It will be open to all paediatric trainees, which will also further enable the senior trainees to provide careers advice in their future roles as educational supervisors and mentors.

\section{G192(P) 'THE DAY THE SIMULATOR DIED' - A PILOT}

1,2LC Budd, 1,2S Pawley. 'Children's Emergency Department, Royal Alexandra Children's Hospital, Brighton, UK; ${ }^{2}$ Department of Paediatrics, Brighton and Sussex University Hospitals NHS Trust, Brighton, UK

\subsection{6/archdischild-2015-308599.186}

Aims We wanted to evaluate the educational value of a new inter-professional simulation day - 'The Day the Simulator Died'. Methods This day comprised introductory lectures, 2 high fidelity simulations of unsuccessful resuscitations including a simulated parent and communication skills sessions addressing breaking bad news and unexpected child death procedures. Immediate feedback was sought and a follow up questionnaire was sent 4 months later.

Results The pilot day had 9 participants -8 answered the follow up questionnaire.

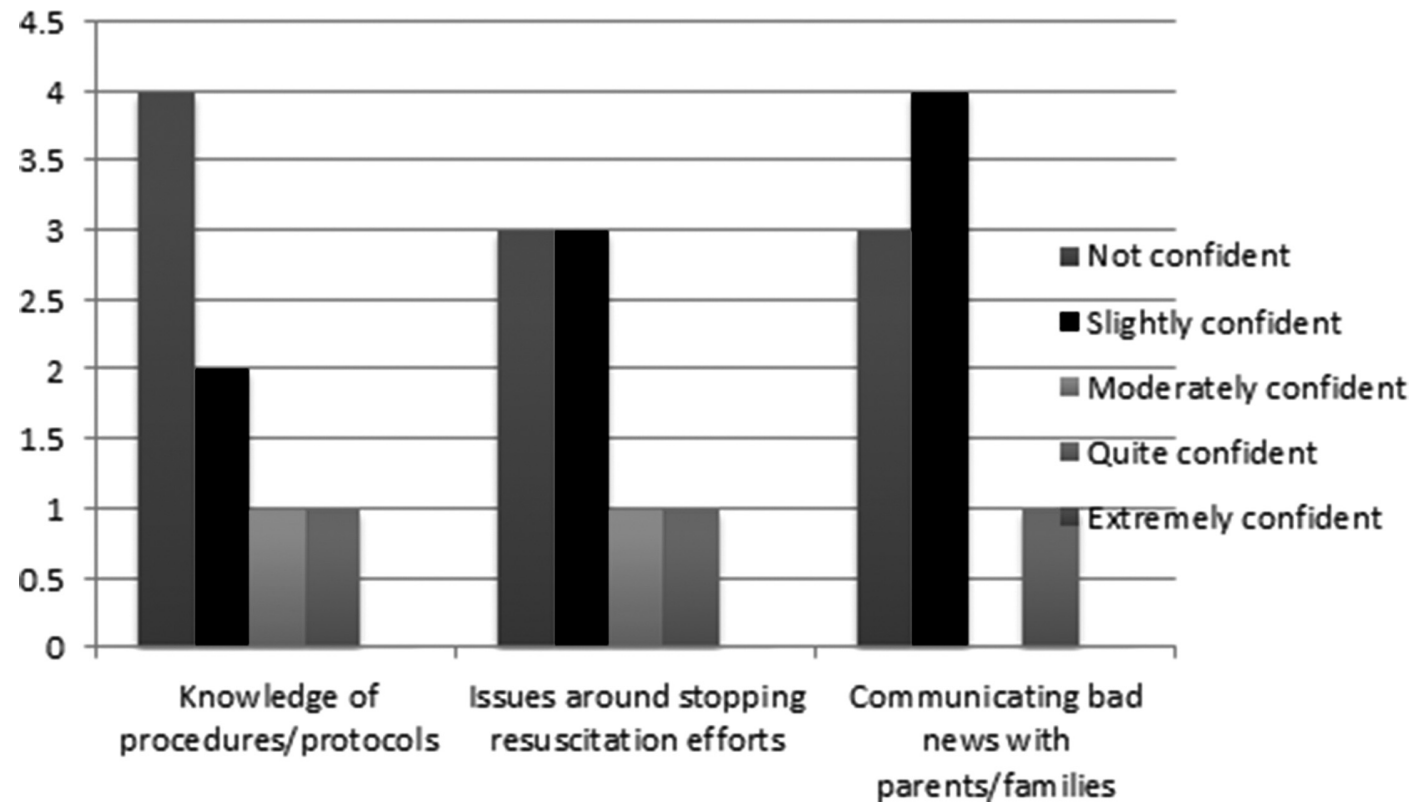

Abstract G192(P) Figure 1 Pre-simulation day confidence 